\title{
Gestão da informação e tecnologias: diretrizes para projetos da interface de museus virtuais no âmbito da autenticidade
}

\author{
Larissa Fernandes Dutra \\ Doutoranda; Universidade Federal de Minas Gerais, Belo Horizonte, MG, Brasil; \\ larissadutraa@gmail.com \\ Cátia Rodrigues Barbosa \\ Doutora; Universidade Federal de Minas Gerais, Belo Horizonte, MG, Brasil; \\ catiarb@eci.ufmg.br \\ Diomira Maria Cicci Pinto Faria \\ Doutora; Universidade Federal de Minas Gerais, Belo Horizonte, MG, Brasil; \\ diomira@uol.com.br
}

\begin{abstract}
Resumo: O objetivo deste estudo é contribuir para a criação de diretrizes para projetos da interface de museus virtuais no que tange à sua autenticidade. Por meio do método dedutivo, ao trabalharmos com a teoria sobre o autêntico, analisou-se um modelo de site de museus virtuais (Era Virtual) para criar indicadores de avaliação de autenticidade dentro desses. Após as análises teórica e prática, elaborou-se um questionário piloto visando validar os indicadores criados e, caso necessário, elaborar outros indicadores a partir da resposta do público. Em seguida, foi definida a amostra da pesquisa, foram aplicados os questionários finais, foram analisados os resultados obtidos e foram, então, criadas as diretrizes para a interface dos museus virtuais. Identifica-se que a autenticidade é um conceito dinâmico que diz respeito tanto a questões verificáveis através da matéria de um objeto, quanto a questões não materiais que emergem da relação entre o homem e esse objeto. A amostra pesquisada acredita que os museus virtuais são autênticos principalmente pelo seu valor informativo.
\end{abstract}

Palavras-chave: Gestão da Informação. Tecnologia da Informação e da Comunicação. Museus Virtuais. Autenticidade. Era Virtual

\section{Introdução}

Ao longo dos últimos anos, principalmente após a segunda metade do século $\mathrm{XX}$, foram percebidas intensas mudanças nos cenários sociais, econômicos e tecnológicos no mundo. Yamaoka (2006) esclarece que os avanços das Tecnologias da Informação e da Comunicação (TIC) permitiram o surgimento 
da internet, propiciando maior velocidade na produção e disseminação de informações, o que tornou a sociedade mais complexa, assim como suas instituições.

Nessa nova era, as grandes corporações mundiais começaram a criar estratégias para a condução de seus negócios baseadas na utilização de recursos informativos. As instituições culturais, a exemplo dos museus, não ficaram imunes a essas mudanças e passaram a aderir também, gradativamente, à gestão da informação como estratégia de ampliação de público e de capital.

Um dos motivos de os museus estarem se preocupando, cada vez mais, com a gestão da sua informação é que, com o aumento do número de instituições museológicas pelo mundo - principalmente no Ocidente -, passou a haver uma brutal diminuição de recursos para a manutenção de todas (CÂNDIDO, 2014). Assim, no intuito de atender às demandas de um público crescentemente interessado por tecnologias, os museus se reinventaram.

Os museus virtuais são resultado desse fenômeno. Essa interface proporciona aos usuários um novo meio de se movimentar pelas galerias de arte e de imergir em contextos culturais sem a necessidade de sair de casa. Configuram-se como uma possibilidade de recuperação de informação especializada, auxiliando pessoas que buscam se informar sobre um ou diversos assuntos instantaneamente. O portal Era Virtual (2018), por exemplo, disponibiliza visitas a museus transportados para a virtualidade criando no usuário, por meio de fotografias em $360^{\circ}$ e ilusão tridimensional, a sensação de estar caminhando dentro dos próprios museus, representados por imagens.

Estudos realizados por Benjamin (1996) retratam, no entanto, que a reprodução de acervos por meio de fotografias deve ser questionada quando a encaramos pela perspectiva da autenticidade. Para o pensador, ao reproduzir-se uma obra, a sua historicidade, o seu valor de culto e a sua unicidade se esvaem (BENJAMIN, 1996). Partindo desse pressuposto, podemos questionar até que ponto os museus virtuais - que detêm as fotografias do museu em meio físico como principais formadoras da sua interface - são, de fato, autênticos. Além disso, a informação transmitida por meio desse acervo virtual pode também ser refletida no âmbito da autenticidade, pois, caso não seja manejada por 
profissionais preparados, torna-se obsoleta - devido à alta dinamicidade do ciberespaço (FORMENTON; GRACIOSO; CASTRO, 2015).

Desse modo, o processo de desenvolvimento desta investigação se pautou pelo interesse em compreender como o público, ao visitar os museus virtuais, percebe a questão do autêntico. Justifica-se esta pesquisa, pois, conforme observado por Choo (2003), uma instituição de sucesso deve se concentrar para criar significados a partir da observação do ambiente em que está inserida e para construir conhecimentos fundamentados nas informações obtidas, para, então, tomar as melhores decisões.

A pesquisa, nesse sentido, foi dividida em cinco fases. A primeira trata da utilização do método dedutivo como ferramenta para o entendimento do termo autenticidade. A segunda consiste na revisão do layout do site Era Virtual no intuito de compreender quais são as principais informações transmitidas por essa plataforma e quais são as possibilidades de navegação dentro da interface. Ao analisar a teoria da pesquisa junto à visita prática, conseguiu-se compor os indicadores de avaliação. Assim, a terceira fase se deu com a elaboração de um questionário piloto objetivando a validação dos indicadores construídos na etapa anterior. A quarta fase tratou da construção e aplicação do questionário final para respondentes de três áreas do conhecimento: Artes, Turismo e Museologia. A quinta destinou-se à análise dos resultados e, então, à criação das diretrizes para a interface de museus virtuais.

\section{A Gestão da Informação em museus à luz de um novo contexto social}

Segundo Cândido (2014), desde a década de 1980, as instituições museais vêm passando por uma mudança contextual ligada tanto aos avanços tecnológicos e científicos da sociedade pós-moderna quanto a crises econômicas que culminaram no recuo dos Estados na manutenção de setores como a cultura. Assim, para conseguirem sobreviver, os museus construíram estratégias que resultassem em captação de público e recursos, como a aproximação de empresas privadas por meio de parcerias e gestão da sua informação para tomadas de decisão assertivas. O Quadro 1 traz alguns fatores que criaram a necessidade da gestão da informação pelos museus na atualidade: 
Larissa Fernandes Dutra, Cátia Rodrigues Barbosa e Diomira Maria Cicci Pinto Faria

Quadro 1 - Fatores envolvidos na gestão da informação em museus

\section{Fatores Internos}

Melhoria do serviço ao visitante

Mais pessoas em cargo de direção

provenientes de corporações,

implementando uma gestão de museus no molde dos negócios

Aumento dos custos de operação e

tentativa de captação de recursos

\begin{tabular}{|c|}
\hline Crescimento das coleções \\
\hline $\begin{array}{c}\text { Dependência da realização de grandes } \\
\text { exposições }\end{array}$ \\
\hline
\end{tabular}

Fonte: Adaptado de Lord e Market (2007).

\section{Fatores Externos}

Aumento do número de museus e acirramento por público

Incremento da educação e aumento da audiência por museus

Novas políticas governamentais culturais e declínio do suporte financeiro governamental Relações com turismo cultural Aproximação das tecnologias como estratégia de captação de público

Quando pensamos, por exemplo, em mais pessoas em cargos de direção das instituições museológicas provenientes de corporações, vimos que, como existe a tendência de as organizações atuais terem uma preocupação crescente com a gestão da sua informação, esse quesito começa também a ser refletido dentro dos espaços museais. O Banco do Brasil, por exemplo, desde 1997 promove ações culturais pelo país, o que culminou na construção dos seus centros de cultura. Para obter dados para a sua área de Marketing, o banco realiza pesquisas no intuito tanto de avaliar o perfil do seu público quanto de detectar informações que subsidiam a sua tomada de decisão.

Em se tratando da dependência da realização de grandes exposições pelos museus atuais e, consequentemente, da tentativa de captação de recursos, percebe-se que a gestão da informação também está fortemente ligada a esse contexto. O processo de decisão sobre qual exposição trazer para um museu utiliza o artifício informativo com o qual o conselho do museu avalia tanto as necessidades e preferências do público quanto o mercado (CÂNDIDO, 2014).

Além disso, percebe-se também uma aproximação dos museus com as novas tecnologias, como no caso da representação do seu acervo em meio virtual. Os museus em âmbito virtual colaboram para que o usuário recupere conteúdo sem necessidade de deslocamento e ainda podem incrementar a atividade turística - já que pesquisas revelam que o museu no ciberespaço consegue instigar pessoas a se deslocarem ao seu correspondente físico 
Larissa Fernandes Dutra, Cátia Rodrigues Barbosa e Diomira Maria Cicci Pinto Faria

(DUTRA; FARIA, 2017). Assim, é importante que prossigamos com uma breve exposição sobre o surgimento e conceituação dos museus em meio virtual.

\section{A Ciência da Informação e suas interfaces: o nascimento dos Museus}

\section{Virtuais}

Ao se refletir sobre o advento e uso das novas tecnologias na perspectiva da Ciência da Informação, constata-se uma turbulência nesse campo de conhecimento especialmente no que tange à representação, armazenagem e recuperação de informações. Segundo Alvarenga (2003), com os mecanismos de representação da informação se dinamizando, houve uma extrapolação dos limites dos tradicionais catálogos informativos para bases de dados online, como as bibliotecas digitais e os aplicativos de conteúdo diversos.

Essa dinamização vem ocorrendo também nas instituições museológicas. Os museus, para além de suas galerias tradicionais com quadros e etiquetas informativas, passaram a incluir em suas dependências salas com instalações multimídia, que acabaram por facilitar os meios de recuperação da informação e de aprendizado pelo público. Outro exemplo se revela na inserção dessas instituições no ciberespaço através dos museus virtuais.

Historicamente, o surgimento desses campos de interação virtual ocorreu como parte do desenvolvimento tecnológico advindo da Primeira Guerra Mundial. Segundo Rocha e Eckert (2000), foi a necessidade de prospecção do espaço aéreo que originou a tela dos computadores, ao permitir o mapeamento de imagens de segurança militar para a tela de um monitor. Atualmente, essas interfaces podem se configurar de várias formas, a exemplo do cinema, em que a imagem se movimenta com independência do observador, ou como no museu virtual, onde o espectador se move no espaço para contemplar as exposições do museu em meio online. Neste caso, as telas de obras de arte funcionam como janelas-interface, podendo ser desmembradas em muitas outras janelas, concebidas como uma coleção de diferentes blocos de informações. Para isso, são criados dispositivos que conseguem operar com a imagem através dos comandos de movimento do visitante. 
Larissa Fernandes Dutra, Cátia Rodrigues Barbosa e Diomira Maria Cicci Pinto Faria

Para Carvalho (2005), o museu representado no espaço virtual demonstra uma superação das limitações impostas pelos métodos tradicionais de exposição:

Coleções logicamente relacionadas de objetos digitais compostos de variados suportes que, em função de sua capacidade de proporcionar conectividade e vários pontos de acesso, possibilita-lhe [sic] transcender métodos tradicionais de comunicar e interagir com visitantes, seus objetos e as informações relacionadas, podendo ser disseminados em todo o mundo. (ANDREWS; SCHWEIBENZ, 1998, p. 21 apud CARVALHO, 2005, p. 80) ${ }^{1}$.

A autora ainda complementa que a riqueza desse tipo de museu está intimamente ligada à democratização do acesso às exposições, que permite um contato mais amplo e interativo com os objetos expostos, dando a possibilidade de criação de redes de discussão sobre determinada temática (CARVALHO, 2005).

Assim, compreendendo que ainda existem diferentes perspectivas sobre o conceito e sobre o uso dos museus virtuais, define-se para a presente pesquisa que museus virtuais se encontram em meio virtual; são representações de museus que existem em meio físico; oferecem tours virtuais por meio dos quais o visitante poderá conhecer suas dependências e são plataformas essencialmente informativas, que divulgam cultura por intermédio de seu acervo digitalizado.

Desse modo, o próximo tópico terá como finalidade a apresentação do ambiente de estudo desta pesquisa, o site de museus virtuais da Era Virtual.

\subsection{Ambiente de estudo: os museus virtuais do site Era Virtual}

O projeto Era Virtual foi desenvolvido no ano de 2008, visando à promoção do patrimônio cultural brasileiro por meio da criação de visitas virtuais. Para isso, seus organizadores viajam pelo país e, a partir de fotografias produzidas nos locais visitados, realizam uma compilação de imagens junto a dados e recursos interativos, tornando possível, por meio de programação computacional, visitar, virtualmente, as dependências desses museus.

Em se tratando de layout, a Era Virtual está dividida em quatro seções principais: (I) Home; (II) Projeto; (III) Visitas virtuais; (IV) Como navegar (ERA VIRTUAL, 2018). A primeira seção apresenta um panorama geral do site abarcando as principais visitas virtuais do projeto e seus links para acesso. $\mathrm{Na}$ 
Larissa Fernandes Dutra, Cátia Rodrigues Barbosa e Diomira Maria Cicci Pinto Faria

segunda seção é apresentado o projeto de uma forma geral, elucidando seu histórico, coordenadores e parceiros. Na seção de Visitas virtuais, o usuário encontra todos os museus ${ }^{2}$ que se podem visitar pelo site.

Na seção denominada Como navegar, o site disponibiliza informações referentes aos seus recursos de navegação. Inicialmente, explica-se como percorrer as salas e exposições, e essa movimentação pode ser feita de até duas formas. A primeira delas é por meio das setas espalhadas pelo museu, que são usadas quando o visitante desejar entrar ou sair de determinada sala, ou virar à esquerda ou à direita. $\mathrm{O}$ visitante também pode se orientar utilizando a caixa seletora, na qual estão especificadas todas as salas pertencentes a cada museu, bastando que o usuário escolha qual deseja visitar, formando o seu próprio percurso de imersão. Para que o visitante possa ter acesso ao acervo, é utilizada a ferramenta de zoom, bastando clicar no ícone referente a cada peça para ver sua imagem em detalhes, e são exibidos também dados das obras como nome, ano, material, autoria, entre outras informações.

\section{Autenticidade: construindo um Panorama Teórico}

Para Lira (2009), um dos maiores desafios na identificação de um determinado bem como autêntico consiste nas dificuldades terminológicas da palavra autenticidade. Segundo a autora, a definição contemporânea dessa palavra começa a tomar forma após o Iluminismo no século XVIII, quando a elite intelectual europeia constata, por meio de fontes variadas de informação, que algumas das escrituras bíblicas antes tidas como autênticas tinham sido corrompidas com acréscimos ao longo do tempo (LIRA, 2009). A partir de então, o autêntico passa a assumir um significado de oposição ao forjado, ligando-se a verdade, legitimidade e genuinidade.

Com o passar dos anos, muitos autores foram desenvolvendo importantes pesquisas no campo da autenticidade, inclusive trazendo inovações para a terminologia. Ricœur (2000), por exemplo, acredita que a autenticidade está na mente do ser humano, não sendo uma condição inerente ao objeto. Para ele, a ideia de que os objetos podem existir em um estado falso não é correta, já que 
Larissa Fernandes Dutra, Cátia Rodrigues Barbosa e Diomira Maria Cicci Pinto Faria

todos os estados pelos quais passou o objeto desde a sua criação são testemunhos confiáveis e verdadeiros de sua própria história (RICCEUR, 2000).

Por outro lado, para Benjamin (1996), por exemplo, as obras de arte são produzidas por meio de um processo criativo que dá especificidade para cada objeto. Assim, não há como pensar que todos os objetos são autênticos:

\begin{abstract}
Mesmo na reprodução mais perfeita, um elemento está ausente: o aqui e agora da obra de arte, sua existência única, no lugar em que ela se encontra. É nessa existência única, e somente nela, que se desdobra a história da obra. Essa história compreende não apenas as transformações que sofreu, com a passagem do tempo, em sua estrutura física, como as relações de propriedade em que ela ingressou. [...] O aqui e agora do original constitui o conteúdo da sua autenticidade, e nela se enraíza uma tradição que identifica esse objeto, até os nossos dias, como sendo aquele objeto, sempre igual e idêntico a si mesmo. (BENJAMIN, 1996, p. 2).
\end{abstract}

Ou seja, para Benjamin (1996) a aura do objeto é perdida a partir de sua reprodução e então podemos distinguir objetos autênticos e inautênticos.

Aprofundando as discussões acima, será apresentado a seguir um panorama quanto ao termo autenticidade por cada uma das áreas do conhecimento que embasam teoricamente o artigo: a Teoria e Crítica da Arte, o Turismo Cultural e a Ciência da Informação.

\title{
4.1 Autenticidade na Teoria e Crítica da Arte
}

A discussão sobre a noção de autenticidade no campo da Teoria e Crítica da Arte, de uma forma geral, segue em torno de dois entendimentos básicos: o de autenticidade nominal e o de autenticidade expressiva. Segundo Dutton (2005), a autenticidade nominal está associada à identificação correta das origens de uma obra. Para tanto, a verificação da autenticidade de uma obra de arte pode ser considerada uma questão baseada em procedimentos científicos, aplicados por especialistas das Artes, da Química etc. É da autenticidade nominal que vem a expressão esse é um autêntico Portinari, pois ela é capaz de identificar as obras pertencentes a cada artista, diminuindo as possibilidades de plágio.

O segundo entendimento se volta para o caráter de um objeto como expressão verdadeira de valores e crenças de um indivíduo ou uma sociedade. Ou seja, a autenticidade expressiva remete a uma visão do que algo deverá ser 
Larissa Fernandes Dutra, Cátia Rodrigues Barbosa e Diomira Maria Cicci Pinto Faria

por definição social. Dutton (2005) revela que essa tem uma relação com o público no estabelecimento do significado da obra. É nesse ponto que se percebe que mesmo sendo a obra original e sua cópia idêntica, ao original são atribuídos valores históricos que crescem na medida em que a obra sobrevive no tempo, e é aí que temos a principal diferença, segundo Benjamin (1996), entre a obra original e a sua reprodução.

\subsection{Autenticidade no Turismo Cultural}

O conceito de autenticidade utilizado no estudo das motivações e experiências turísticas foi introduzido por MacCannell com a publicação do livro $O$ turista em 1976. Segundo Cunha (2011), embora o conceito comece a ser bastante difundido nos últimos anos, ele não é estável na literatura turística. Wang (1999) foi o primeiro a se debruçar sobre o significado do termo diferenciando a autenticidade no turismo em três: a objetiva, a construtiva e a existencial, sendo as duas primeiras relacionadas ao objeto turístico e a última à experiência turística.

A autenticidade objetiva, nesse sentido, refere-se à autenticidade dos objetos, como aqueles expostos em museus por exemplo. De acordo com Harvey (2004), podemos compreender que a autenticidade objetiva está relacionada com as origens de certo objeto, mas ao contrário do que acontece na Teoria e Crítica da Arte, o fim não é a comprovação da genuinidade de um dado objeto, mas sim a transmissão dessa informação de modo acessível ao visitante.

A autenticidade construtiva é o resultado de uma construção social sobre o atrativo visitado. Para Cunha (2011), as coisas surgem como autênticas não porque inerentemente o sejam, mas porque são construídas como tais em termos de crenças ou de perspectivas. Nesse sentido, a autenticidade construtiva é um conceito dinâmico, já que um lugar visitado pode vir a ser considerado como autêntico mesmo que anteriormente a sociedade o percebesse como inautêntico. Um exemplo é o caso da Disney, que anteriormente fora criticada pela construção de uma realidade encenada em um local construído especialmente para turistas, mas hoje é o parque de diversões que mais recebe visitantes no mundo. Em se tratando da autenticidade existencial, essa estaria inteiramente na 
Larissa Fernandes Dutra, Cátia Rodrigues Barbosa e Diomira Maria Cicci Pinto Faria

mente de quem observa ou vive a atividade turística. Como o indivíduo está em constante mudança, a autenticidade passa a ser fruto também de um sistema de valores individuais que sempre se transforma.

\subsection{Autenticidade na Ciência da Informação}

A evolução da Ciência da Informação está ligada à sua relação ao longo dos anos com outras disciplinas que contribuíram para a sua formação (SARACEVIC, 1996). Mesmo que a sua origem como ciência tenha sido dada recentemente, algumas disciplinas como a Diplomática e a Arquivística se destinaram a organizar e gerir o conhecimento antes do seu advento.

A Diplomática, por exemplo, nasceu no século XVII com a finalidade de estabelecer regras para comprovar a autenticidade de documentos eclesiásticos. A Igreja Católica publicou em 1643 os primeiros volumes de Acta Sanctorum, com o objetivo de separar o que era de fato verdadeiro do que era lenda em relação à vida dos santos. Tempos depois, o monge Mabillon noticiou um tratado no qual estabelecia regras para verificar a autenticidade dos documentos. O método consistia em repartir o documento para examiná-lo em seus elementos externos - caráter material, aparência, escritura, sinais especiais, autoria etc. - e elementos internos - componentes que o articulam intelectualmente, como apresenta seu conteúdo (TOGNOLI; GUIMARÃES, 2009).

Com o passar dos anos e o advento das TIC, profissionais ligados a documentos de forma geral se viram despreparados para tratar da quantidade de conteúdo gerado pelos novos sistemas, surgindo um novo desafio: manter os registros criados em meio eletrônico inalterados, de forma a garantir seu acesso e sua autenticidade. Formenton, Gracioso e Castro (2015) afirmam que os documentos eletrônicos são mais desafiadores no que se refere à autenticação devido à forma como são produzidos e transmitidos e ao fato de serem mais facilmente alterados e de por vezes se encontrarem em plataformas dinâmicas.

Desse modo, pela Ciência da Informação, principalmente através das novas tecnologias, começa-se a pensar em documentos autênticos ou inautênticos dentro de ambientes virtuais. É o caso dos museus virtuais, que, conforme visto anteriormente, detêm um acervo digitalizado que transmite 
Larissa Fernandes Dutra, Cátia Rodrigues Barbosa e Diomira Maria Cicci Pinto Faria

informações cuja fidedignidade profissionais que lidam diretamente com a informação são encarregados de averiguar. Considerando, nesse sentido, que objetos museais expõem informações sobre determinada história ou cultura e que a imagem e o conteúdo desses objetos, quando eles são transportados para ambientes virtuais, perpassam por um processo de representação para recuperação, podemos começar também a refletir sobre a autenticidade desse acervo virtual, tanto no que diz respeito ao objeto transportado para o ciberespaço quanto pela percepção por seu usuário da autenticidade da informação recuperada.

\section{Metodologia}

A primeira fase desta pesquisa utilizou o método dedutivo como ferramenta para a construção de teorias que auxiliem na compreensão do termo autenticidade. Este método se configura como o processo de raciocínio dedutivo, que liga premissas com conclusões, de ideias gerais para casos específicos (LAKATOS; MARCONI, 1991).

Para este artigo, os bancos de dados utilizados para a recuperação de referências quanto à palavra autenticidade foram o Google Acadêmico e o Portal de Periódicos da Coordenação de Aperfeiçoamento de Pessoal de Nível Superior (CAPES), com publicação de 2010 a 2017. A partir de então, foram selecionados os estudos mais relevantes - considerando os objetivos desta investigação - e, assim, foi possível a construção de três premissas básicas em se tratando da autenticidade em museus virtuais: (I) premissa quanto à Dimensão Objetiva: a autenticidade nos documentos digitais envolve questões relacionadas a origem, autoria, integridade e aparência de sua matéria, isso se relaciona também com a veracidade da informação transmitida por meio desses; (II) premissa quanto à Dimensão Construtiva: a autenticidade nos documentos digitais demanda uma aceitação coletiva, somente dessa forma se torna representativa e legítima; isso também se relaciona com a percepção de confiabilidade que o público detém da informação transmitida por meio desses; (III) premissa quanto à Dimensão Reflexiva: a autenticidade nos documentos 
Larissa Fernandes Dutra, Cátia Rodrigues Barbosa e Diomira Maria Cicci Pinto Faria

digitais se encontra na mente dos sujeitos, de forma subjetiva a cada pessoa que se relaciona diretamente com este documento.

A segunda fase da investigação consistiu em avaliar o site Era Virtual baseando-se na verificação do seu conteúdo através de visitas realizadas ao longo da pesquisa. Ao analisar a teoria junto à visita prática, conseguimos compor os indicadores de avaliação de autenticidade nessas plataformas. Um exemplo é o fato de termos, pela teoria de Benjamin (1996), a ideia de que a reprodução das obras de arte retiraria a sua autenticidade. Assim, incluímos esse fator entre os indicadores de autenticidade da premissa (I), que lida com a aparência do objeto. Ou seja, indagamos ao usuário se a visualização das imagens do acervo no museu virtual por meio de fotografias era fator de desfavorecimento da percepção de autenticidade. Através dessa mesma teoria, também inserimos como indicador a noção da dimensão da obra - que é alterada no momento da sua reprodução fotográfica.

Além disso, no momento da visita prática ao site de museus virtuais Era Virtual, nos deparamos com alguns museus em que não era possível o acesso a determinadas salas de exposição que existem no correspondente físico. Deparamo-nos também com anúncios publicitários de patrocinadores do projeto como a Fundação Vale, a Internet Data Center (IDC), dentre outros. Mesmo que esses fatores não estivessem presentes na teoria deste trabalho, foram adicionados como atributos de avaliação de autenticidade nos museus virtuais dentro da premissa (I) porque afetam, de certa forma, a aparência do museu e podem alterar a percepção de autenticidade do usuário. A certeza de utilização ou não desses indicadores para o questionário final se daria após a aplicação do questionário piloto ao público. Caso obtivéssemos retornos de usuários alegando que estes eram indicadores importantes quanto à percepção de autenticidade da interface, eles seriam adicionados ao questionário final e reaplicados para a amostra final da pesquisa.

Em se tratando da premissa (II), segundo a teoria de Formenton, Gracioso e Castro (2015), um dos meios de avaliação construtiva de autenticidade na Ciência da Informação se dá mediante a confiança da sociedade nos métodos que as plataformas digitais utilizam para assegurar que suas 
Larissa Fernandes Dutra, Cátia Rodrigues Barbosa e Diomira Maria Cicci Pinto Faria

informações não sejam manipuladas e falsificadas após a sua criação. Nesse sentido, perguntamos ao usuário se, por meio da visita virtual, considerou a informação recuperada como autêntica e quais os fatores favorecem ou não essa percepção.

Os fatores de favorecimento e desfavorecimento de autenticidade da informação, neste caso, também foram retirados das teorias de Formenton, Gracioso e Castro (2015) e de Freitas (2011) e de outros estudos analisados ao longo da investigação. Como atributo de favorecimento, incluímos as informações são provenientes de instituições confiáveis, os museus virtuais são desenvolvidos por pessoas preparadas, dentre outros. Como atributo de desfavorecimento, adicionamos as questões: informações via internet podem ser alteradas por qualquer um, informações obtidas na internet, se não atualizadas constantemente, ficam desatualizadas com facilidade etc.

Partindo para a premissa (III), que se destina a entender a subjetividade de cada indivíduo na atribuição de autenticidade nos documentos digitais, perguntou-se aos respondentes qual o significado do termo autenticidade, no intuito de identificar a partir de qual viés o participante responderia às questões seguintes. Assim, perguntou-se se, na visão do usuário, o museu virtual - como um todo - seria autêntico ou não e quais os fatores de favorecimento e desfavorecimento dessa avaliação. Para a construção desses indicadores, utilizamos as teorias de Benjamim (1996), Ricœur (2000), Dutton (2005) etc. e chegamos aos seguintes atributos de favorecimento de autenticidade: seu valor informativo, sensação de imersão - sentimento de estar caminhando nas dependências do museu por meio das setas e cursores do mouse, interação por meio de links relacionados na página do museu virtual etc. Como atributo de desfavorecimento, incluímos: a reprodução da obra de arte por meio de fotografias retira a sua autenticidade, falta de interação - área específica para discussão de conteúdo e outras possibilidades de imersão etc.

Assim foram construídos os indicadores, sempre relacionando a visita de Era Virtual com as premissas a que se chegou com o método dedutivo.

Em novembro de 2017, foram aplicados para 29 alunos do curso de Museologia da Universidade Federal de Minas Gerais (UFMG) os questionários 
pilotos. A escolha por essa amostragem se baseou no fato de que, em princípio, o grupo continha pessoas com maior conhecimento sobre museus, podendo contribuir mais profissionalmente para a avaliação dos indicadores. A dinâmica da aplicação dos questionários se baseou na solicitação de que os respondentes entrassem no site Era Virtual e por uma hora fizessem uma visita a um ou mais museus. Passado o tempo, foram entregues os questionários e, após se responder a eles, o processo estava finalizado.

Com o teste, foi possível apurar inconsistências do projeto piloto. O primeiro problema detectado foi o perfil da amostra de pesquisa. Identificou-se que utilizar somente alunos da Museologia como respondentes não seria o ideal para o questionário final, porque alguns dos resultados obtidos com o estudo foram entendidos como enviesados, por serem percepções adquiridas somente de uma área do conhecimento. Outro ponto de inconsistência foi a percepção de que ainda faltava incluir indicadores no questionário final para a construção de diretrizes mais relevantes. As respostas dos entrevistados contribuíram para essa constatação.

Um exemplo deste caso é o do indicador sensação de tédio e desinteresse como desfavorecedor da percepção de autenticidade do museu virtual. Muitos respondentes do questionário piloto indicaram - por meio das questões abertas que não se sentiam imersos na visita virtual, o que gerava uma sensação de tédio e até mesmo desinteresse na visita ao museu. Alguns, inclusive, alegaram sentir vertigem ao utilizar o recurso de $360^{\circ}$ do museu. Assim, para definir se o atributo seria de fato um desfavorecedor da percepção de autenticidade, ele foi acrescentado ao questionário final, ligando-se aos estudos da premissa (III).

Em se tratando da amostra final, definiu-se que, como a teoria desenvolvida se baseou em três áreas específicas do conhecimento, o grupo a ser entrevistado poderia também ser pertencente a esses mesmos campos. Para determinar a amostragem, comparou-se com nossa amostra a amostra de pesquisas que se propuseram a desenvolver estudos semelhantes ao nosso. Padaratz (2015), por exemplo, cujo estudo objetiva aprimorar a experiência do usuário em museus virtuais de Moda por meio de um projeto de usabilidade, realizou um experimento laboratorial com 15 estudantes da Universidade do 
Larissa Fernandes Dutra, Cátia Rodrigues Barbosa e Diomira Maria Cicci Pinto Faria

Estado de Santa Catarina. Percebeu-se ao longo desse estudo que o fato de se aplicar um questionário que depende de tarefas faz com que pesquisadores não consigam administrar altas amostragens, porque o processo demanda tempo e laboratórios equipados, o que o torna mais desafiador.

Desse modo, aplicaram-se os questionários finais em maio de 2018 com a mesma dinâmica do questionário piloto - nas disciplinas de Patrimônio Cultural no Mundo Moderno e Contemporâneo, Economia do Turismo, Arte e Vanguardas do Século XX e Fundamentos das Artes Digitais. As duas primeiras pertenciam aos cursos de Museologia e Turismo da UFMG e as outras duas, ao curso de Artes da Universidade do Estado de Minas Gerais (UEMG). Foram aplicados 67 questionários, dos quais 33 da Museologia, 19 do Turismo e 15 das Artes. A última fase da investigação se destinou à análise dos resultados e à criação das diretrizes.

\section{Apresentação e Análise dos resultados}

Em se tratando da dimensão objetiva, observa-se, no Gráfico 1, que a presença do áudio guia durante a visita ao museu virtual, o desenho das vias de imersão que conectam as obras de arte e a qualidade da imagem foram, respectivamente, os indicadores que mais favoreceram a percepção de autenticidade dos respondentes. Em se tratando dos fatores de desfavorecimento, o atributo mais votado foi a presença dos anúncios publicitários durante a visita, seguido das salas que existem no museu físico, mas não estão acessíveis no virtual.

Sobre este último fator, um dos participantes da investigação comenta que a possibilidade de acessar os museus virtuais quando os seus espelhos físicos estão fechados para visita presencial ou quando as exposições já não estão mais em cartaz, os torna um banco de informações permanente na nuvem, daí a sua importância fundamental. Uma reflexão, nesse sentido, pode ser feita acerca do Museu Nacional, localizado no Rio de Janeiro e consumido por um incêndio em setembro de 2018. Enquanto o museu permanecer fechado, o seu público pode, por meio do Museu Nacional Virtual, acessar mais de 750 itens da sua coleção retomando a memória de um acervo destruído, tragicamente, pelas chamas. Além disso, um dos benefícios de se obter um acervo digital, pode ser 

projetos da interface de museus virtuais no âmbito da autenticidade

Larissa Fernandes Dutra, Cátia Rodrigues Barbosa e Diomira Maria Cicci Pinto Faria

visto, segundo Moura et al (2012) sob a perspectiva da auditoria das coleções perdidas ou parcialmente deterioradas, contribuindo para tomadas de decisão em caso de calamidades como essa (MOURA, et al, 2012). Retomando o Gráfico 1, dos atributos restantes, a representação do museu por intermédio de fotografias e a falta de noção de tamanho das obras se mostraram fatores de maior favorecimento da percepção de autenticidade do que desfavorecimento.

Gráfico 1 - Atributos de influência de autenticidade nos museus virtuais

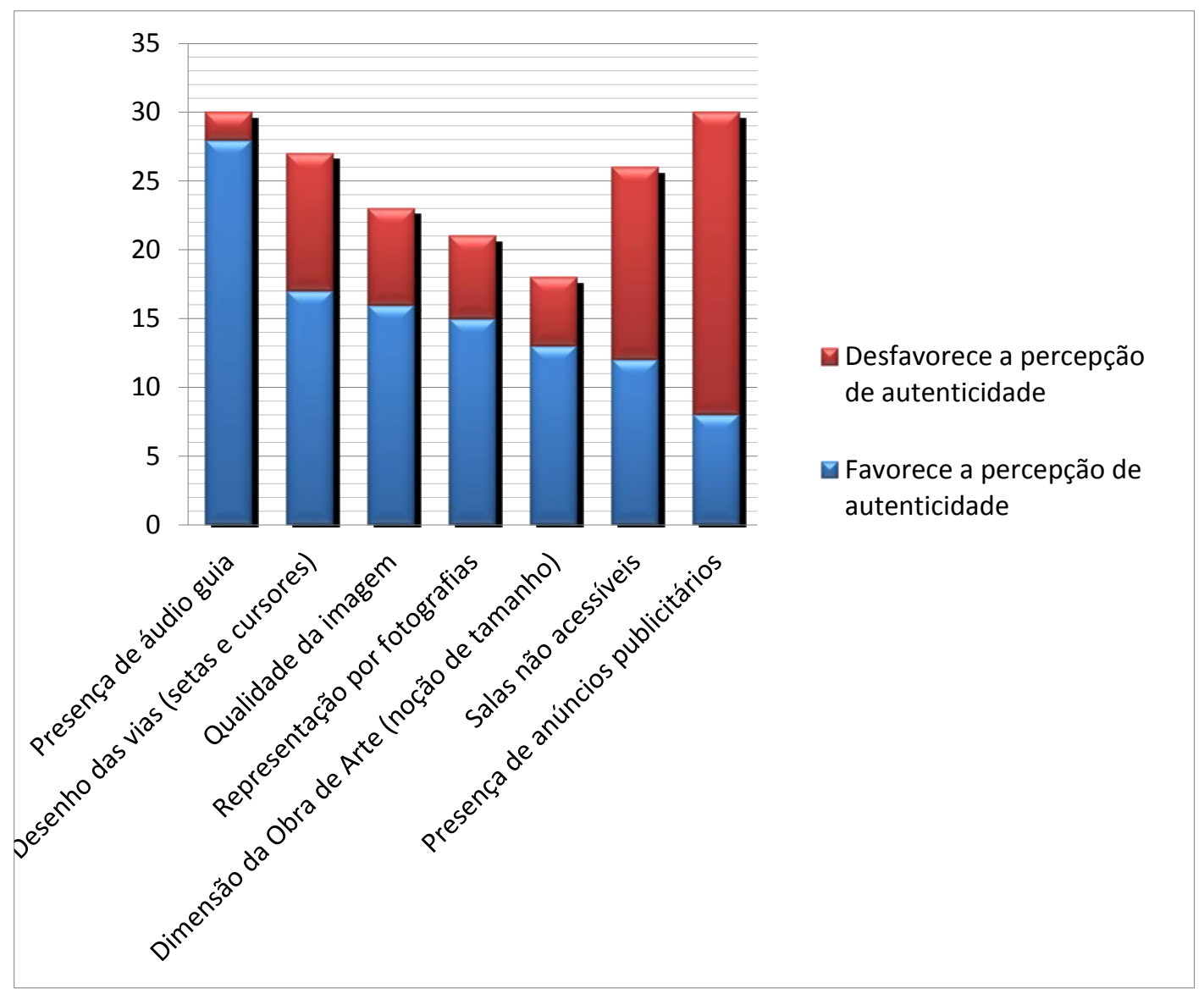

Fonte: Elaborado pelas autoras.

Ainda avaliando a dimensão objetiva do museu virtual, quando os respondentes foram questionados sobre o que é importante em se tratando da visualização do acervo para a percepção de autenticidade, verificou-se que a visualização de detalhes da obra de arte com nitidez foi o fator de maior importância, com 58 escolhas dos 67 entrevistados, seguida da visualização em vistas múltiplas (frente, costas e laterais) e da visualização de outras imagens que contextualizem a obra de arte (registros históricos, objetos relacionados), 
Larissa Fernandes Dutra, Cátia Rodrigues Barbosa e Diomira Maria Cicci Pinto Faria

cada uma com 55 escolhas. Vale ressaltar que os participantes podiam escolher mais de uma opção nesse caso.

Questionou-se a amostra sobre que tipo de informações o museu virtual deveria disponibilizar para favorecer a percepção de autenticidade do usuário (os entrevistados podiam escolher mais de uma opção). Dos 67 entrevistados, 66 consideraram que tanto a contextualização histórica do objeto quanto os dados do artista eram as informações mais importantes a serem disponibilizadas. $\mathrm{Na}$ sequência, com 45 escolhas, estão os materiais utilizados na obra, seguidos da sua dimensão e da sua medida (43 escolhas).

Em se tratando das possibilidades de busca de informação especializada dentro do museu virtual, perguntou-se quais formas de busca de informação um museu virtual devia oferecer para melhorar a recuperação da sua informação e, consequentemente, sua autenticidade. $\mathrm{O}$ resultado mostrou que os usuários entendem que a busca por tipologias de museus facilitaria a recuperação de informações, assim como a busca por palavras-chave e por períodos históricos, em segundo lugar. Um dos respondentes alegou que uma busca importante para a recuperação de informações seria pelo tipo do objeto como, por exemplo, cadeiras, esculturas etc.

Quando questionados sobre se, de forma geral, consideravam que a informação obtida por meio da visita ao museu virtual é autêntica, 89\% dos entrevistados disseram que sim. Os atributos que mais favoreceram essa percepção foram as informações provirem de uma instituição confiável, com 43 escolhas, seguido de os museus virtuais serem desenvolvidos por pessoas preparadas (historiadores, museólogos, artistas etc.), com 39 escolhas.

Quando questionados sobre quais atributos desfavoreciam a percepção de autenticidade da informação do museu virtual, $46 \%$ dos entrevistados alegaram que as informações obtidas na internet, se não atualizadas constantemente, ficam desatualizadas com facilidade. Além disso, 30\% dos respondentes confiavam mais na informação transmitida no museu físico que no virtual.

No intuito de aprofundar o entendimento sobre a autenticidade das informações transmitidas pelos museus virtuais contemplados na Era Virtual, 
Larissa Fernandes Dutra, Cátia Rodrigues Barbosa e Diomira Maria Cicci Pinto Faria

buscou-se contato com a gestão de um dos museus apresentados no site. A gestão do referido museu nos informou que o contrato para a criação do museu virtual é firmado com a Era Virtual, contemplando o desenvolvimento de plataforma de visitação imersiva e interativa, mas que, para cada alteração de conteúdo, necessita-se uma nova contratação dos serviços. Caso existam, por exemplo, atualizações de estudos referentes a essas obras e essas resultem em dados diferentes daqueles que estão contemplados no museu virtual, a gestão do museu precisará pagar uma nova quantia para que a Era Virtual atualize suas informações para disponibilização ao público. Nos casos em que a gestão do museu virtual não detiver recursos imediatos para atualização de suas informações, poderá ocorrer uma recuperação de conteúdo de confiança duvidosa por parte dos usuários. Exemplo disso é dado pela gestora entrevistada, que nos afirmou nunca ter atualizado as informações do museu virtual em questão desde o seu desenvolvimento pela Era Virtual.

Continuando a tratar sobre a autenticidade da informação nos museus virtuais visitados, quando questionados sobre se a informação transmitida foi adequada em relação ao seu conteúdo, $40 \%$ dos respondentes consideraram a informação adequada; 37\%, muito adequada; $18 \%$, adequada medianamente e $5 \%$ consideraram pouco adequada. Isso quer dizer que, de uma forma geral, os usuários consideraram não haver muitos problemas quanto ao conteúdo do site, já que $77 \%$ o consideraram muito adequado ou adequado. Quando questionados sobre se a informação transmitida pelo museu virtual foi adequada quanto a como navegar pelo portal, 34\% avaliaram a informação como adequada, seguidos de $27 \%$ que votaram em adequado medianamente; de $18 \%$, em muito adequado; de $13 \%$, em pouco adequado e de $8 \%$, em inadequado. Neste quesito, os relatos dos participantes da pesquisa trataram principalmente das dificuldades de se mover pelas salas de exposições, de fazer leituras sobre as informações das peças do acervo e, principalmente, de iniciar a visita pelo museu virtual.

Em se tratando da dimensão construtiva da autenticidade, questionou-se a frequência com que os participantes visitavam museus virtuais e quais os seus propósitos quando o faziam. Do total da amostra, $45 \%$ nunca haviam visitado um museu virtual; $22 \%$ haviam visitado um museu virtual uma vez; $18 \%$, entre 
Larissa Fernandes Dutra, Cátia Rodrigues Barbosa e Diomira Maria Cicci Pinto Faria

duas e cinco vezes; $12 \%$, entre cinco e dez vezes e 3\%, mais de dez vezes. Este resultado nos mostra que por mais que 55\% dos respondentes já tivessem visitado museus virtuais no mínimo uma vez, um grande número de pessoas nunca havia visitado um museu virtual.

Com o objetivo de entender quais eram os principais usos que os entrevistados que visitavam os museus virtuais davam a essa interface, perguntamos aos respondentes que já haviam visitado museus virtuais quais os propósitos da sua visita. Do total, $41 \%$ visitavam por curiosidade; $25 \%$, por diversão e lazer; 20\%, para buscar informações relevantes para pesquisas e o restante, 14\%, visitava museus virtuais no intuito de buscar informações que auxiliassem a visita presencial ao museu.

Quanto à dimensão reflexiva, questionamos se, de uma forma geral (incluindo informações, objetos, percurso imersivo etc.), os respondentes consideravam o museu virtual visitado autêntico. A maioria dos participantes (84\%) considerou que sim. Quando questionados sobre quais os principais fatores que favoreceram a percepção de autenticidade (lembrando que os respondentes poderiam escolher mais de um indicador), 44 do total de 67 informantes afirmaram que o valor informativo do museu virtual favorecia a percepção de autenticidade, seguidos de 34 indivíduos que escolheram as galerias de arte e obras do museu (acervo). Com 33 escolhas cada, está o valor artístico e histórico, a visita em perspectiva $360^{\circ}$ e as fotografias em alta definição e, por fim, a interação por meio de conteúdo sonoro.

Em se tratando dos fatores que desfavoreceram a percepção de autenticidade no museu virtual, temos, em primeiro lugar, a sensação de tédio e desinteresse do usuário, que não se sentiu, segundo os resultados da pesquisa, imerso na visita virtual. Em segundo lugar, temos a reprodução da obra de arte por meio de fotografias que acabam alterando a percepção de autenticidade e em terceiro, o fato de não existir uma rota pré-determinada para visitar o museu.

\section{Diretrizes}

As diretrizes propostas nesta seção se configuram como um conjunto de instruções que servirão para que gestores e desenvolvedores das plataformas de 
Larissa Fernandes Dutra, Cátia Rodrigues Barbosa e Diomira Maria Cicci Pinto Faria

museus virtuais utilizem, em seus projetos de interface, as ponderações

apresentadas, principalmente no que tange à autenticidade e à informação.

Quadro 2 - Diretrizes quanto às dimensões objetiva, construtiva e reflexiva da autenticidade em museus virtuais

\begin{tabular}{|c|c|c|c|}
\hline Indicador & $\begin{array}{l}\text { Resultado da } \\
\text { pesquisa }\end{array}$ & Diretriz & $\begin{array}{l}\text { Dimensão } \\
\text { relacionada }\end{array}$ \\
\hline $\begin{array}{l}\text { 1. Desenho das } \\
\text { vias de imersão } \\
\text { que conectam } \\
\text { as obras de } \\
\text { arte e galerias } \\
\text { do museu } \\
\text { virtual }(M V)\end{array}$ & $\begin{array}{l}\text { O indicador é } \\
\text { favorecedor da } \\
\text { percepção de } \\
\text { autenticidade do } \\
\text { usuário. }\end{array}$ & $\begin{array}{l}\text { - A aparência dos caminhos de } \\
\text { imersão em um MV deve ser } \\
\text { esteticamente agradável, com } \\
\text { harmonização dos elementos da } \\
\text { interface (cores, layout, imagens, } \\
\text { textos etc.); } \\
\text { - O acesso às vias de imersão deve ser } \\
\text { elaborado de forma a facilitar a } \\
\text { movimentação do usuário. Balões } \\
\text { informativos sobre como se mover no } \\
\text { espaço são primordiais para que o } \\
\text { visitante não se sinta desorientado na } \\
\text { interface; } \\
\text { - O ambiente do museu virtual deve } \\
\text { ser, além de envolvente e atrativo, } \\
\text { prático e organizado, para que o } \\
\text { usuário não se perca nos comandos de } \\
\text { navegação. }\end{array}$ & Objetiva \\
\hline $\begin{array}{l}\text { 2. Presença de } \\
\text { áudio guia } \\
\text { durante a visita }\end{array}$ & $\begin{array}{l}\text { O indicador é } \\
\text { favorecedor da } \\
\text { percepção de } \\
\text { autenticidade do } \\
\text { usuário. }\end{array}$ & $\begin{array}{l}\text { - A navegação com a utilização de } \\
\text { guias de áudio possibilita descrições } \\
\text { detalhadas dos objetos e dispõe o } \\
\text { conteúdo de maneira mais cativante } \\
\text { ao usuário; } \\
\text { - A presença de áudio guia em outros } \\
\text { idiomas colabora para a maior } \\
\text { acessibilidade da interface. }\end{array}$ & Objetiva \\
\hline $\begin{array}{c}\text { 3. Qualidade } \\
\text { da imagem do } \\
\text { MV }\end{array}$ & $\begin{array}{c}\text { O indicador é } \\
\text { favorecedor da } \\
\text { percepção de } \\
\text { autenticidade do } \\
\text { usuário. }\end{array}$ & $\begin{array}{l}\text { - A elaboração de um museu virtual } \\
\text { com imagens de alta qualidade, com } \\
\text { potencial de ampliação para exame da } \\
\text { superfície da peça do acervo, eleva a } \\
\text { percepção de autenticidade do } \\
\text { usuário. }\end{array}$ & Objetiva \\
\hline $\begin{array}{l}\text { 4. Presença de } \\
\text { anúncios } \\
\text { publicitários } \\
\text { durante a visita } \\
\text { ao } M V\end{array}$ & $\begin{array}{c}\text { O indicador é } \\
\text { desfavorecedor } \\
\text { da percepção de } \\
\text { autenticidade do } \\
\text { usuário. }\end{array}$ & $\begin{array}{l}\text { - Os anúncios publicitários dentro de } \\
\text { um MV devem se localizar na página } \\
\text { de abertura da interface, evitando que } \\
\text { sejam inseridos ao longo das galerias } \\
\text { de visitação para que o usuário não se } \\
\text { sinta desmotivado a continuar com a } \\
\text { visita. }\end{array}$ & Objetiva \\
\hline
\end{tabular}


Larissa Fernandes Dutra, Cátia Rodrigues Barbosa e Diomira Maria Cicci Pinto Faria

\begin{tabular}{|c|c|c|c|}
\hline $\begin{array}{l}\text { 5. Visualizar a } \\
\text { obra de arte em } \\
\text { vistas múltiplas } \\
\text { (frente, costas, } \\
\quad \text { laterais) }\end{array}$ & $\begin{array}{l}\text { O indicador é } \\
\text { favorecedor da } \\
\text { percepção de } \\
\text { autenticidade do } \\
\text { usuário. }\end{array}$ & $\begin{array}{l}\text { - Quanto maiores as possibilidades de } \\
\text { visualização da obra de arte, mais o } \\
\text { usuário terá uma leitura completa do } \\
\text { objeto; } \\
\text { - É importante que as vistas do objeto } \\
\text { estejam integradas com o conteúdo } \\
\text { textual e com outras mídias } \\
\text { disponíveis, para que imagem e } \\
\text { contexto se complementem, } \\
\text { garantindo a satisfação do usuário. }\end{array}$ & Objetiva \\
\hline $\begin{array}{c}\text { 6. Busca de } \\
\text { informação } \\
\text { especializada } \\
\text { no } M V\end{array}$ & $\begin{array}{c}\text { Os meios de } \\
\text { busca de } \\
\text { informação } \\
\text { especializada no } \\
\text { MV mais } \\
\text { interessantes para } \\
\text { os usuários são } \\
\text { por tipologias de } \\
\text { museus e por } \\
\text { palavras-chave. }\end{array}$ & $\begin{array}{l}\text { - O MV deve contemplar formas } \\
\text { diferentes de busca de informação, } \\
\text { para diferentes tipos de usuários; } \\
\text { - Localização de objetos do acervo } \\
\text { por tipologias do museu ou palavras- } \\
\text { chave é interessante para que o } \\
\text { usuário consiga filtrar a sua busca } \\
\text { com maior objetividade; } \\
\text {-Possibilidade de compartilhamento } \\
\text { de conteúdo e informações com } \\
\text { outros visitantes do MV por meio de } \\
\text { salas de bate-papo aumenta a } \\
\text { interatividade da plataforma. }\end{array}$ & Construtiva \\
\hline $\begin{array}{l}\text { 7. Adequação } \\
\text { do conteúdo do } \\
\text { site }\end{array}$ & $\begin{array}{l}\text { O indicador é um } \\
\text { favorecedor da } \\
\text { percepção de } \\
\text { autenticidade do } \\
\text { usuário. }\end{array}$ & $\begin{array}{l}\text { - Os textos informativos do museu } \\
\text { devem estar adaptados à web, ou seja, } \\
\text { devem se apresentar de forma } \\
\text { dinâmica e fragmentada (sem a } \\
\text { utilização de textos longos que levem } \\
\text { ao desinteresse do usuário). }\end{array}$ & Construtiva \\
\hline $\begin{array}{c}\text { 8. Usos dados } \\
\text { pelo usuário ao } \\
M V\end{array}$ & $\begin{array}{c}\text { Os usuários } \\
\text { utilizam o MV na } \\
\text { maioria das vezes } \\
\text { por curiosidade } \\
\text { ou por diversão e } \\
\text { lazer. }\end{array}$ & $\begin{array}{l}\text { - Ambientes imersivos em ilusão } \\
\text { tridimensional, fotografias } 360^{\circ} \text { e } \\
\text { interatividade levam o público a se } \\
\text { interessar por visitar o MV; } \\
\text { - Para aqueles usuários que utilizam o } \\
\text { MV como fonte de informação, é } \\
\text { ideal que se tenha uma organização } \\
\text { lógica e prática do conteúdo com } \\
\text { estrutura simples e direta. }\end{array}$ & Construtiva \\
\hline $\begin{array}{c}\text { 9. O valor } \\
\text { informativo do } \\
M V\end{array}$ & $\begin{array}{l}\text { O indicador é o } \\
\text { maior } \\
\text { favorecedor da } \\
\text { percepção de } \\
\text { autenticidade do } \\
\text { usuário na } \\
\text { dimensão } \\
\text { reflexiva. }\end{array}$ & $\begin{array}{l}\text { - A informação nos MVs pode se } \\
\text { revelar por meio de áudios, imagens e } \\
\text { vídeos e outro meio interativo que a } \\
\text { tecnologia proporcionar; } \\
\text { - A informação deve se revelar ao } \\
\text { público de formas variadas, tanto por } \\
\text { meio de games educativos, por } \\
\text { exemplo, no intuito de atingir os } \\
\text { jovens, quanto por meio de artigos } \\
\text { científicos linkados à página para } \\
\text { suportar a necessidade de } \\
\text { pesquisadores e estudantes. }\end{array}$ & Reflexiva \\
\hline
\end{tabular}


Larissa Fernandes Dutra, Cátia Rodrigues Barbosa e Diomira Maria Cicci Pinto Faria

\begin{tabular}{|c|c|l|c|c|}
\hline $\begin{array}{c}\text { 10. Sensação } \\
\text { de tédio e }\end{array}$ & $\begin{array}{c}\text { Este atributo é } \\
\text { desfavorecedor }\end{array}$ & $\begin{array}{l}\text { - Para que a sensação de tédio e } \\
\text { desinteresse de alguns usuários deixe }\end{array}$ & Reflexiva \\
desinteresse do & da percepção de & de existir, é sugestão que se realizem & \\
usuário & autenticidade do & estudos de público para identificar & \\
& usuário. & $\begin{array}{l}\text { quais são os principais interesses e } \\
\text { perfis dos visitantes dos museus } \\
\text { virtuais. }\end{array}$ & \\
\hline
\end{tabular}

Fonte: Elaborado pelas autoras.

\section{Considerações Finais}

Museus virtuais têm a capacidade de estabelecer conexões entre os objetos e o visitante, criando um diálogo interativo, o que transcende os métodos tradicionais de comunicação dos museus em meio físico. A partir das funções interativas, proporciona que seu visitante mergulhe em um dilúvio informacional explorando o assunto que lhe parecer mais conveniente sem a necessidade de sair de casa.

Os objetivos delineados no início desta investigação foram atingidos de maneira satisfatória, dentro dos limites impostos pelos recursos e tempo disponíveis. Tanto o questionário final quanto a amostra de pesquisa poderão ser modificados com a elaboração de novos estudos para que outras diretrizes se revelem, possibilitando o maior desenvolvimento dessas interfaces e contribuindo para a experiência do público.

Um resultado importante deste artigo foi que os participantes consideraram como maior influenciador da autenticidade do museu virtual o seu valor informativo. Ou seja, o usuário reconhece as possibilidades de acesso a conteúdo variado por meio dessas interfaces. Assim, conforme ideias de Malraux (1996), podemos compreender que para os museus virtuais, a reprodução de obras de arte por intermédio de fotografias e as informações disponibilizadas para contextualizá-las se configuram como uma forma de dinamizar o contato do público com o mundo da arte.

Isso nos mostra que, por mais que autores como Benjamim (1996) ressaltem que a unicidade de uma obra de arte é excluída a partir do momento de sua reprodução, sua disponibilidade à coletividade aumenta na medida em que esta é reproduzida, aproximando o objeto do espectador. Isso faz com que indivíduos que não têm acesso à arte pessoalmente, por fatores geográficos ou 

projetos da interface de museus virtuais no âmbito da autenticidade

Larissa Fernandes Dutra, Cátia Rodrigues Barbosa e Diomira Maria Cicci Pinto Faria

outros diversos, agora consigam se aproximar dessa realidade pelos museus no ciberespaço. Nesse sentido, o valor de acessibilidade dessa plataforma é indiscutível. Percebe-se, assim, que a função dessas novas plataformas se aproxima muito à de complementação dos museus tradicionais, no sentido de torná-los mais acessíveis, não substituindo uma realidade, mas criando outras formas de apreciá-la dentro da sociedade da informação que vivemos.

\section{Referências}

ALVARENGA, Lídia. Representação do Conhecimento na perspectiva da Ciência da Informação em tempo e espaço digitais. Encontros Bibli, Florianópolis, v. 8, n. 15, p. 18-40, 2003.

BENJAMIN, Walter. A obra de arte na era da sua reprodutibilidade técnica. In: BENJAMIN, Walter. Obras escolhidas: magia e técnica, arte e política. 2. ed. São Paulo: Brasiliense, 1996.

CÂNDIDO, Manuelina Maria Duarte. Gestão de museus, diagnóstico museológico e planejamento: um desafio contemporâneo. 2. ed. Porto Alegre: Medianiz, 2014.

CARVALHO, Rosane Maria Rocha. As transformações da relação museu e público: a influência das tecnologias da informação e comunicação no desenvolvimento de um público virtual. 2005. Tese (Doutorado em Ciência da Informação) - Curso de Pós-Graduação em Ciência da Informação, Universidade Federal do Rio de Janeiro, Rio de Janeiro, 2005.

CHOO, Chun Wei. A organização do conhecimento: como as organizações usam a informação para criar significado, construir conhecimento e tomar decisões. São Paulo: Senac, 2003.

CUNHA, Licinio. Autenticidade e Inovação: factores de renovação dos destinos turísticos maduros. Journal of Tourism Studies, Lisboa, v. 4, n. 4, p. 9-27, 2011.

DUTRA, Larissa Fernandes; FARIA, Diomira Maria Cicci Pinto. Sociedades contemporâneas e o mundo de telas: um estudo acerca do museu virtual do Circuito Liberdade In: FÓRUM ABRATUR, 17., 2017, Recife. Anais [...]. Recife: Universidade Federal de Pernambuco, 2017. p. 123-124.

DUTTON, Denis. Authenticity in art. In: LEVINSON, Jerrold (org.). The Oxford Handbook of Aesthetics. New York: Oxford University Press, 2005. p. 258-274. 
Larissa Fernandes Dutra, Cátia Rodrigues Barbosa e Diomira Maria Cicci Pinto Faria

ERA VIRTUAL. Portal Era Virtual. Minas Gerais, 2018. Disponível em: http://eravirtual.org/. Acesso em: 20 dez. 2018. Acesso em: 10/03/2018.

FORMENTON, Danilo; GRACIOSO, Luciana Souza; CASTRO, Fabiano Ferreira. Revisitando a preservação digital na perspectiva da Ciência da Informação: aproximações conceituais. Revista Digital de Biblioteconomia e Ciência da Informação, Campinas, v. 13, n. 1, p. 170-191, 2015.

HARVEY, William Robert. Authenticity and experience among visitors at a historic village. 2004. Thesis (Master of Science in Forestry) - Virginia Polytechnic Institute and State University, Blacksburg, 2004.

LAKATOS, Eva Maria; MARCONI, Maria de Andrade. Metodologia Científica. São Paulo: Atlas, 1991.

LIRA, Flaviana Barreto. Patrimônio cultural e autenticidade: montagem de um sistema de indicadores para o monitoramento. 2009. Tese (Doutorado em Desenvolvimento Urbano) - Curso de Pós-Graduação em Desenvolvimento Urbano, Universidade Federal de Pernambuco, Recife, 2009.

LORD, Gail Dexter; MARKET, Kate. The manual of strategic planning for museums. Lanham: AltaMira Press, 2007.

MALRAUX, Andre. Discours à l'assemblee nationale française 1945-1976. [s.l.]: Assemblée Nationale, 1996.

MOURA, Ithalo Bruno Grigório; LIMA, João de Deus; NETO, Francisco Milton Mendes; MAIA, Paulo Sérgio Sousa. MUSERT: um museu virtual em 3D para a preservação do Patrimônio Histórico e Cultural. In: JORNADA DE INFORMÁTICA DO MARANHÃO, 4., 2012, Maranhão. Anais [...].

Maranhão: Universidade Federal do Maranhão, 2012, s/p.

PADARATZ, Aline. Experiência do usuário em museus virtuais de moda: diretrizes para o projeto da interface. 2015. Dissertação (Mestrado em Design) Curso de Pós-Graduação em Design, Universidade do Estado de Santa Catarina, Florianópolis, 2015.

RICCEUR, Paul. Entre retórica e poética: Aristóteles. In: RICCEUR, Paul. A metáfora viva. São Paulo: Loyola, 2000. cap. 1, p. 17-75.

ROCHA, Ana Luiza Carvalho; ECKERT, Cornelia. A cidade, o tempo e a experiência de um museu virtual: pesquisa antropocronotopológica nas novas tecnologias. Iluminuras, Porto Alegre, v. 1, n. 1, p. 2-25, 2000.

SARACEVIC, Tekfo. Ciência da Informação: origem, evolução e relações. Perspectivas em Ciência da Informação, Belo Horizonte, v. 1, n. 1, p. 41-62, 1996 

projetos da interface de museus virtuais no âmbito da autenticidade

Larissa Fernandes Dutra, Cátia Rodrigues Barbosa e Diomira Maria Cicci Pinto Faria

TOGNOLI, Natalia Bolfarini; GUIMARÂES, José Augusto Chaves. A Diplomática Contemporânea como base metodológica para a organização do conhecimento arquivístico: perspectivas de renovação a partir das ideias de Luciana Duranti. In: CONGRESO INTERNATIONAL SOCIETY OF KNOWLEDGE ORGANIZATION, 9., 2009, Valencia. Anais [...]. Valencia: Universidad Politécnica de Valencia, 2009. p. 23-35.

WANG, Ning. Rethinking Authenticity in Tourism Experience. Annals of Tourism Research, [s. l.] v. 26, n. 2, p. 349-370, 1999.

YAMAOKA, Eloi. Organização e representação do conhecimento: uma proposta de arquitetura. In: CARVALHO, I. M.; MENDES, S. P.; VERAS, V. M. (org.). Gestão do conhecimento: uma estratégia empresarial, conhecer é preciso! Brasília: J J Gráfica e Comunicação, 2006.

\title{
Information management and technologies: guidelines for virtual museum interface projects in with respect to authenticity
}

\begin{abstract}
The purpose of this study is to contribute to the creation of guidelines for virtual museum interface projects regarding their authenticity. Through the deductive method, when working with theories about the authentic, we analyzed a virtual museum site model (Era Virtual) to create authenticity assessment indicators for virtual musem sites. After theoretical and practical analyses, a pilot questionnaire was designed to validate, through the response of the public, the indicators we developed and to develop others, if necessary. Then, we defined our sample, the final questionnaires were applied, the results obtained were analyzed, and the guidelines for virtual museum interface were set out. We found that authenticity is a dynamic concept that concerns both issues verifiable through the subject matter of a digital object and non-material issues that emerge from the relationship between a person and that object. The sample surveyed believed that virtual museums were authentic mainly for their informative value.
\end{abstract}

Keywords: Information management. Information and Communication Technology. Virtual museums. Authenticity. Era Virtual.

Recebido: 04/05/2019

Aceito: 17/09/2019 
${ }^{1}$ ANDREWS, James. SCHWEIBENZ, Werner. A New Medium for Old Masters: The Kress Study Collection Virtual Museum Project. Art Documentation: Journal of the Art Libraries Society of North America, v. 17, no. 1, p. 19-27. Apud Carvalho (2005)

${ }^{2}$ Museu Pietro Ubaldi; Museu de Sant'ana; Memorial MG Vale; Museu Histórico Victor Lucas; Museu do Inmetro; Museu Vale; Museu da Memória Republicana; Museu Imperial; Museu do Judiciário Mineiro; Museu do Universo; Museu de Ciência e Técnica; Museu de Arte Sacra; Museu da Inconfidência; Museu do Diamante; Memorial Tancredo Neves; Casa Guimarães Rosa; Museu Casa Guignard; Museu Histórico Abílio Barreto; Museu Victor Meireles; Museu Nacional do Mar; Museu da República; Museu do Oratório; Museu de Artes e Ofícios; Casa Cora Coralina. Disponível no site Era Virtual (2018) na guia Visitas virtuais. 